\title{
Neoplasm of the spinal cord: I mplications for clinical care to improve symptom management and functionality
}

\author{
Vishwa S. Raj ${ }^{1}$, J oanna Edeker ${ }^{2}$ \\ 1.Department of Physical Medicine and Rehabilitation, Carolinas Rehabilitation, USA. 2. Department of Physical Therapy, \\ Carolinas Rehabilitation, USA.
}

Correspondence: Vishwa S. Raj. Address: Department of Physical Medicine and Rehabilitation, Carolinas Rehabilitation, 1100 Blythe Boulevard, Charlotte, NC 28203 USA. Email: Vishwa.raj@carolinashealthcare.org

Received: January 30, 2013

Accepted: March 14, 2013

Online Published: March 21, 2013

DOI : $10.5430 /$ cns.v1n2p14

URL: http://dx.doi.org/10.5430/cns.v1n2p14

\section{Abstract}

Individuals suffering from spinal cord neoplasm have shown improved survival however long term plans of care designed to improve functionality, quality of life, and symptom control are not well defined. Many practitioners may not be aware of nursing and rehabilitation interventions that can improve quality of life (QOL) and functionality in this patient population. The purpose of this review is to provide an overview of the primary sources of spinal cord tumors, understand general medical interventions, define treatment options that may improve symptom management, and explain how treatment options and physical rehabilitation can improve functionality and quality of life. An extensive literature review was performed using multiple databases, including pubmed.gov and Ovid, as well as individual journal and textbook articles. Several studies were examined, and it was found that patients experienced improvement in functionality, mood, quality of life, and survival after participation in rehabilitation programs. However, plans of care must factor account for prognosis and medical co-morbidities for maximal improvement in outcomes.

\section{Key words}

Functionality, Rehabilitation, Spinal cord tumor, Symptom control

\section{Introduction}

Cancer rehabilitation is defined as helping a person with cancer increase independence to obtain maximum physical, social, psychological, and vocational functioning ${ }^{[1]}$. Individuals who participate in rehabilitation programs have been shown to make functional gains, in spite of the fact that they have significant medical co-morbidities ${ }^{[2]}$. The goals of rehabilitation interventions in the cancer population are to alleviate symptomatic complaints and provide palliation, improve quality of life (QOL), restore or prevent the decline of function, and minimize the ability of cancer to negatively affect a person's ability to perform their normal day to day activities ${ }^{[3]}$. An interdisciplinary team approach, including interventions provided by rehabilitation nursing, physiatry, and both physical and occupational therapy, can help to maximize outcomes for this patient population. 
The spinal cord tumor population provides a unique set of challenges for patients, caregivers, and the clinical team, when considering the functional deficits from spinal cord involvement, medical co-morbidity due to cancer, and individual life expectancy ${ }^{[4]}$. However, rehabilitation interventions remain a vital component in the care of individuals with spinal cord injury secondary to cancer, specifically in the cases of tumors that originate within the spinal cord or from other organ systems that have invaded the spinal cord and vertebrae ${ }^{[5]}$. When combined with improvements in medical, radiation, and surgical oncology care, rehabilitation can serve to integrate patient and family efforts to improve function with a multidisciplinary team approach and prevent future complications from neurological compromise ${ }^{[6]}$. Rehabilitation remains particularly important in helping individuals and their families adjust to the medical and functional care requirements, given that a high percentage of patients with metastatic spinal cord compression are able to discharge to home ${ }^{[7]}$. Though life expectancy has improved for patients suffering from spinal tumors due to both earlier detection and advances in oncological treatment, issues surrounding patient fragility and complications from concurrent medical treatment have prevented full access to rehabilitative services ${ }^{[8]}$. The purpose of this review is to understand the existing literature related to rehabilitation of spinal cord tumors and the importance of rehabilitation in improving functionality and quality of life for individuals with a diagnosis of spinal cord tumors.

\section{Key learning objectives}

- Spinal cord tumors are a significant cause of morbidity and mortality.

- Spinal tumors can be categorized as primary versus secondary or metastatic, and can have neurological effects due to direct spinal cord involvement, external compression due to tumor progression outside of the spinal cord, or vertebral body instability leading to impingement of the spinal cord.

- Primary treatment of spinal cord tumors involves surgical resection, radiation therapy, and chemotherapy.

- Nursing and rehabilitation interventions can be used to improve functionality and quality of life

\section{Methodology}

An extensive literature review was performed using multiple medical research databases, including Pubmed, Medline Plus, and Ovid. Several website and textbook articles were also used for general background information and relevant community resources. A general search query for spinal cord tumors and physical rehabilitation yielded 272 citations. Articles for consideration were further refined using the keywords: functionality, rehabilitation, nursing care, and QOL. This search was completed in January of 2013. Relevance of citation was narrowed based on the areas of rehabilitation and nursing care for patients with spinal cord neoplasm. Inclusion criteria for article utilization during this review was specific to rehabilitation outcomes for spinal cord tumor patients and general cancer rehabilitation patients, nursing care for oncological patients, and clinical management for patients dealing with spinal cord injury. Including all databases and information sources, 83 references were sited in this review.

\section{Prevalence and pathology of spinal cord tumors}

Metastatic spinal tumors, or tumors that have originated from organ systems other than the spinal cord or vertebrae, are common, with over 18,000 annual new cases diagnosed in North America and up to 70\% prevalence in patients with cancer with known metastases ${ }^{[9]}$. They represent ten percent of new onset spinal cord injuries (SCI) due to tumor compression, and are a relatively common diagnosis in the rehabilitation setting, with a prevalence of up to $26 \%$ of non-traumatic SCI admissions, where non-traumatic SCI is defined as insult to the spinal cord from a medical condition rather than a physical external injury to the spine ${ }^{[10]}$. Tumors can be either primary, or arising from the central nervous system (CNS) directly, or secondary with an origin distant to the spinal cord from another organ system. A majority of spinal cord tumors are metastatic lesions, which account for $85 \%$ of all oncological SCI. Typical sources of secondary metastatic disease includes lung, breast, kidney, prostate, and thyroid cancers. Bone is the third most common site of 
metastases and vertebrae are the most common site of metastases in the bone ${ }^{[11]}$. Symptomatic lesions are most often diagnosed in the thoracic region presenting with motor incomplete paraplegia, though cadaveric studies have also shown the most common site of vertebral tumor burden in the lumbar spine ${ }^{[10]}$.

Secondary metastatic disease, however, is the most common cause of neurological dysfunction for spinal cord tumor, and typically presents with external compression of the spinal cord from a tumor that is located outside of the meninges (see Figure 1). The manner by which tumor spreads to these areas include tumor embolization, where cancer cells spread through the blood vessels and seed at distant sites, or seeding of tumor through the lymphatic system in to the pre-vertebral and epidural spaces. These tumors may be either osteolytic, which involves destruction of normal bone, or osteoblastic from the deposition of new bone. Both types of lesions can cause vertebral body instability, which leads to retropulsion of bony fragments into the epidural space after vertebral body collapse and impingement of the spinal cord. The tumor itself may also grow and externally compress the thecal sac anteriorly, thus compressing the spinal cord and epidural venous plexus. Lung and breast cancer typically affect the cervical and thoracic spine, whereas prostate, colon, or pelvic cancers metastasize to the lumbar and sacral spine ${ }^{[14]}$. Lung metastases to the spinal column often yield the poorest survival rate, with 50\% survival rate at 1 month and at best $16 \%$ after 24 months. On the other hand, breast and prostate cancer have the best survival rates with $44 \%$ for breast and $25 \%$ for prostate after 24 months ${ }^{[15]}$. There is, however, a tail to survival curves and some patients may require high levels of long term care for at least 3 years or more ${ }^{[16]}$.

Figure 1. Extradural spinal cord tumor

Adapted from: Gebauer GP, Farjoodi P, Sciubba DM, Gokaslan ZL, Riley LH 3rd, Wasserman BA, Khanna AJ. Magnetic resonance imaging of spine tumors: classification, differential diagnosis, and spectrum of disease. J Bone Joint Surg Am. 2008; Suppl 4:146-162.

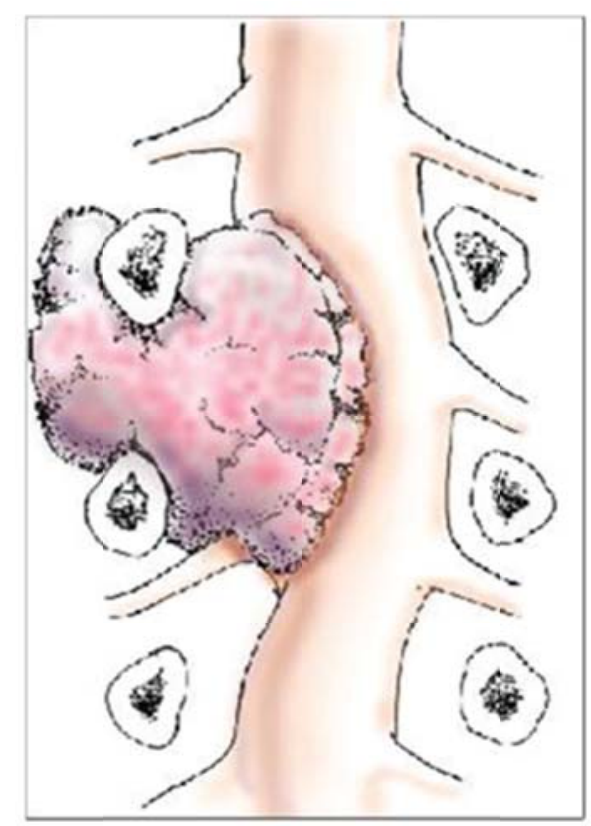

Primary tumors of the spinal cord are less common than secondary tumors. These tumors grow beneath the dura mater of the spinal cord, and are categorized as meningiomas, neurofibromas, and schwannomas (see Figure 2). Most are cured with surgical resection because they are well circumscribed and do not become entangled with either the spinal cord or dural sheath ${ }^{[12]}$. Tumors that actually grow from the spinal cord itself are relatively rare, and account for only $4-5 \%$ of all primary CNS lesions. Although 56\% of these tumors are described as benign and 31\% are malignant (with the remainder being described as indeterminate pathology), they can still have significant neurological implications due to mass effects within the spinal cord (see Figure 3). Ependymomas and astrocytomas represent the majority of primary spinal tumors that arise from actual neural cells. These diagnoses have variable involvement of the spinal cord, ranging from focal involvement of a few centimeters or diffuse entanglement along the entire length of the spinal cord. This in turn leads to significant variability regarding their neurological and functional implications. Low grade astrocytomas and ependymomas have better rates of cure if completely resected, whereas high grade astrocytomas have a poorer prognosis $^{[13]}$. 
Figure 2. Intradural extramedullary spinal cord tumor

Adapted from: Gebauer GP, Farjoodi P, Sciubba DM, Gokaslan ZL, Riley LH 3rd, Wasserman BA, Khanna AJ. Magnetic resonance imaging of spine tumors: classification, differential diagnosis, and spectrum of disease. J Bone Joint Surg Am. 2008; Suppl 4:146-162.
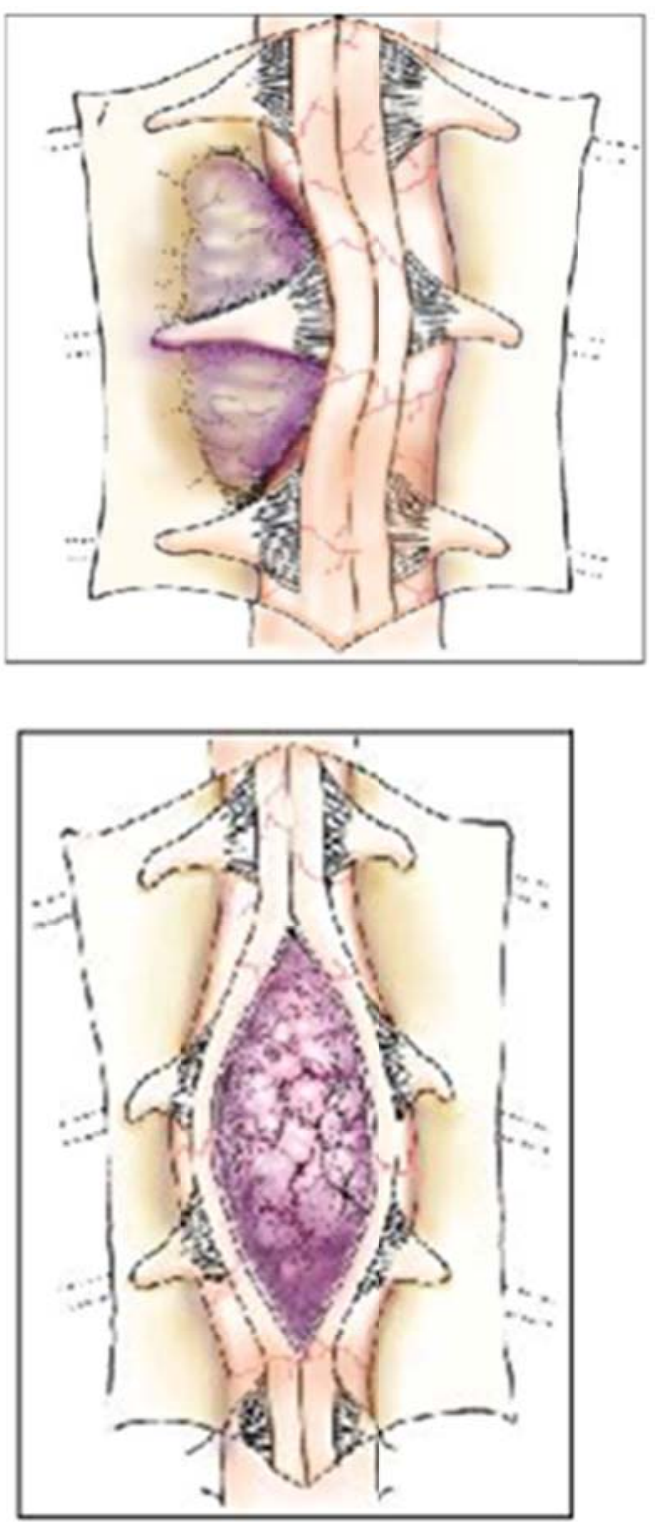

Figure 3. Intradural intramedullary spinal cord tumor

Adapted from: Gebauer GP, Farjoodi P, Sciubba DM, Gokaslan ZL, Riley LH 3rd, Wasserman BA, Khanna AJ. Magnetic resonance imaging of spine tumors: classification, differential diagnosis, and spectrum of disease. J Bone Joint Surg Am. 2008;Suppl 4:146-162.

\section{Primary treatment for spinal cord tumors}

When an individual is diagnosed with a spinal tumor, the main interventions for treatment include surgery, radiation therapy, and chemotherapy. However, the approach will vary depending on the stability of the spine, neurological status, and pain ${ }^{[17]}$. When possible, surgical resection of the tumor is recommended and has been shown to improve survival rates by at least 6 months ${ }^{[18]}$. It is appropriate to consider surgery when patients present with paraplegia lasting not more than 12-24 hours in individuals with prior radiation to the spine, spinal instability, or bony compression of the spinal cord. Radiation therapy should also be considered as early as possible post-operatively and with a focused treatment plan of relatively short duration ${ }^{[19]}$. The primary goals for surgical management are to preserve neurological function and reduce pain, with as minimal intervention as possible to prevent further medical complications ${ }^{[20]}$. Although radiation therapy can be used alone for treatment, it is generally applied for symptomatic relief of metastatic lesions or as a secondary treatment after gross total resection of a tumor. Chemotherapy, however, may also be a first line of treatment for certain types of primary spinal cancers, such as lymphoma, neuroblastoma, and germ cell tumors. Interestingly, both lymphoma and germ cell tumors can originate from the substance of the CNS and are not necessarily metastatic from the lymphatic or 
reproductive systems. Chemotherapy can also be used in the treatment of metastatic disease to the spine for breast, prostate, and myeloma. Steroids are often used as part of a chemotherapeutic regimen, as they can decrease oxidation injury and ischemic edema at the CNS level ${ }^{[21]}$. It is often recommended to use gastrointestinal prophylaxis to limit possible ulceration with concurrent steroid use.

Surgery offers the best potential to maintain ambulation status for patients who were ambulatory before the resection of tumor ${ }^{[22]}$. It also yields improved Frankel grade classification, a common measure of the completeness of a spinal cord injury, by at least one level postoperatively and decreased pain symptoms ${ }^{[23]}$. When combined with radiation therapy, surgery has shown gains regarding bladder dysfunction, the ability to void without an indwelling urinary catheter, and pain ${ }^{[24]}$. These combined effects are particularly important when complete surgical resection is not possible, as is the case for certain higher grade intramedullary astrocytoma tumors ${ }^{[25]}$. Positive prognostic factors for ambulation when receiving radiation therapy include treatment with glucocorticoids and intervention less than 12 hours after the loss of ability to walk. With improved ambulation status, patients generally experienced less pain ${ }^{[26]}$. For prostate cancer with metastases to the spine specifically, improvements in mobility, daily life activities, and sphincter control were noted after radiation therapy ${ }^{[27]}$. Unfortunately, even with gross total resection, up to $20 \%$ of late stage deterioration can be expected from tumor recurrence ${ }^{[28]}$.

\section{Control of symptoms and rehabilitation nursing interventions}

Many of the difficulties in managing spinal cord tumors revolve around the neurological symptoms that arise either from mass effects of the tumor on the nervous system or vertebral body instability. Neuronal pathways are often affected due to direct spinal cord compression, plexopathy, or radiculopathy. Disruption of these networks leads to deficits below the level of the injury, and alteration of basic neurological functions. Along with expected medical co-morbidities from oncological diagnoses, these areas of dysfunction can be an important focus to improve symptomatic management with the application of rehabilitation nursing principles ${ }^{[29]}$.

The most common symptomatic complaint in individuals suffering from spinal cord tumor is pain ${ }^{[29-31]}$. Increased levels of back pain often present several months prior to neurological decline, and can be an early indicator of metastatic disease in the cancer patient ${ }^{[32,33]}$. Although it can be variable in nature, pain generally becomes more constant as metastatic disease progresses. Common causes of pain include vertebral body lesions causing bony destruction and activation of pain receptors, spinal cord compression, vertebral body instability, or spinal nerve root impingement ${ }^{[29]}$. Considerations should be made for post-operative pain syndromes, radiation therapy, and chemotherapy, as they also can lead to worsening pain symptoms in the cancer patient ${ }^{[34]}$. Although this may be counterintuitive, both radiation and chemotherapy can have destructive effects on the CNS and peripheral nervous system, and lead to neuropathic pain syndromes in the cancer patient. The quality and nature of discomfort may vary according to the location of the tumor ${ }^{[35]}$. For instance, impingement of nerve roots may cause radicular symptoms that radiate in the distribution of an affected nerve, whereas involvement of the vertebral body may be focal to the back at the same level of the spine. In individuals with spinal instability, treatment options may include external bracing with orthotic support to maintain anatomic alignment and decompress neurological pain generators. In addition, modalities such as heating packs, ice, ultrasound, and electrical stimulation also may have a role in pain relief. Caution should be used with any modality that can promote increased blood flow, as the potential exists for metastatic spread of disease through tumor cell seeding. However, the clinical effects of pain relief may outweigh potential disease progression, especially if the disease process is significantly metastatic and tumor has already spread by different mechanisms. In addition, oral medications can be used in the treatment of cancer pain. The World Health Organization has developed an analgesic ladder to guide clinicians regarding appropriate medication options for clinical management. Classifications include non-steroidal anti-inflammatories, anti-convulsants, tricyclic antidepressants, steroids, and opioids ${ }^{[36]}$. Careful attention to the side effect profile of these medications is 
important, as these may directly impact an individual's functional or medical status. For neuropathic pain specifically, both gabapentin and pregabalin have been shown to decrease symptoms associated with spinal cord and nerve injury ${ }^{[37-40]}$. However, therapeutic interventions, such as fluidotherapy and desensitization exercises have also shown potential for improvement of neuropathic pain ${ }^{[41]}$. Finally, consideration should be made for interventional pain management procedures, such as epidural steroid injections under fluoroscopy, kyphoplasty, or surgical implantation of morphine pumps for symptoms that are not responsive to less invasive interventions.

Due to their location, spinal cord tumors commonly cause neurological bowel dysfunction ${ }^{[35]}$. The abnormality stems from direct compression of the spinal cord and CNS, with a clinical presentation consistent with upper motor neuron disease. However autonomic and lower motor neuron effects can also be noted due to external compression of the nerves from tumor and toxic neuropathic effects from chemotherapy. Typically for the bowels, this leads to impaired gastrointestinal (GI) motility in the small bowel and proximal colon, and difficulties with evacuation of stool from the distal colon and rectum secondary to hyperreflexic anal tone. For these reasons, individuals often suffer from constipation and impaction ${ }^{[42]}$. Care should be taken for individuals utilizing opioid medications, as these can also lead to increased stool retention, constipation, and decreased GI motility. Symptoms may be worsened by immobility and malnutrition, with potential to exacerbate pain secondary to colonic distention. One method to counteract bowel dysfunction includes a regulated bowel program, which is an effective method for bowel evacuation and pain prevention with defecation ${ }^{[6,43,44]}$. The use of oral stool softeners, such as docusate or fiber based products, are helpful to maintain appropriate firmness of the stool. However, it should be noted that fiber based products may delay stool transmission through the bowels. In principle, stool softeners promote easier motility of stool throughout the GI system. In addition, oral laxatives, such as senna or bisacodyl, can stimulate motility within the proximal bowel. Distally in the colon and rectum, contact irritants, such as bisacodyl suppositories, and reflex mechanisms initiated with the use of digital stimulation of the anus can help evacuate stool within the rectal vault. Caution must be taken with digital stimulation due to increased risk of mucosal fragility, and digital stimulation is not initiated in patients with neutropenia or severe thrombocytopenia ${ }^{[45]}$. Standards have not been established regarding critical lab values to avoid digital stimulation, however, common thresholds include absolute neutrophil count less than 1,000 and platelet count less than 20,000.

Timing of evacuation can be established per patient preference. The primary focus of this program is to prevent incontinent bowel movements and allow adequate evacuation of the bowels within 60 minutes of initiation ${ }^{\text {[46-49] }}$. Bowel programs scheduled 30 minutes after a meal may be more effective as they take advantage of the gastro-colic reflex, which promotes GI emptying. To prevent impaction, a program should be performed at least every two days ${ }^{[42,49,50]}$. Depending on the tumor locations, some individuals suffer from lower motor neuron signs of neurogenic bowel, with decreased responsiveness to reflex mechanisms in the rectum. Hence, digital stimulation will not lead to a reflex contraction in the rectum with relaxation of the anus. In these cases, oral bulk forming agents such as psyllium or polycarbophil, which work by remaining undigested in the bowel and absorbing water to improve stool consistency and firmness, as well as manual disimpaction should be performed daily as the main method of evacuation ${ }^{[49]}$. Again, special consideration to avoid digital manipulation of the rectal mucosa should be given in cases of neutropenia and severe thrombocytopenia.

Bladder dysfunction is also a complication of spinal epidural compression, and presents with a variety of symptoms, such as: urgency, frequency, retention, incontinence, and frequent urinary tract infections (UTI) ${ }^{[29,35]}$. Based on the site of the tumor, a neurogenic bladder may result in either upper or lower motor neuron symptoms, depending on the compression of the suprasacral or sacral spinal cord and roots. Signs of an upper motor neurogenic bladder include bladder and urethral sphincter hypertonia, causing frequent and uncontrolled urination or incoordination between the bladder and urethral sphincter which prevents relaxed emptying. Typically the bladder has higher pressures with low volumes of urine. Lower motor neuron symptoms typically include bladder hypotonia with large volumes of urinary retention, placing the patient at risk for vesicoureteral reflux and kidney damage. The goals of bladder management are to empty the bladder effectively, maintain adequate bladder pressures, prevent hydronephrosis and vesicoureteral reflux, sustain social continence, and reduce risk of kidney disease and UTI ${ }^{[50]}$. The primary diagnostic used to determine the type of neurogenic bladder is 
urodynamic testing. It is important to clarify the type of dysfunction in order to determine the most appropriate and safe method of urinary evacuation. Methods for bladder management in this patient population include: timed voiding such that an individual will schedule voids throughout the day to prevent excessive accumulation of urine in the bladder; intermittent catheterization during which a temporary catheter is placed into the bladder at scheduled intervals throughout the day to empty to the bladder if it cannot empty on its own; and indwelling catheters in which the catheter will remain in the bladder for long periods of time and remains attached to a collection bag to prevent soiling ${ }^{[29]}$. Caution is again necessary with neutropenia and severe thrombocytopenia, and vigilance is needed with any type of catheterization due to the increased risk of UTI secondary to exposure of the bladder to the external environment. Appropriate positioning for catheterization may vary according to body habitus and the level of spinal cord injury, but can be achieved either in the seated position or while lying supine.

Decreased or absent sensation of the skin secondary to neurological impairment can increase the patient's risk of pressure ulcer development. Individuals suffering from cancer generally maintain a catabolic state, thus leading to an increased risk of skin breakdown ${ }^{[51]}$. Therefore, this patient population is at an even greater risk of skin breakdown due to the cancer and SCI diagnoses together. Several factors may exacerbate pressure ulcerations, such as moisture due to prolonged sitting and decreased mobility, bowel and bladder incontinence, and malnutrition. Pressure ulcers are preventable, and maintenance of skin integrity is vital ${ }^{[35]}$. Education of the patient should include appropriate techniques for pressure relief as well as information regarding the importance of nutrition ${ }^{[35,52]}$. Examples of pressure relief include physically shifting positions while seated every 15 minutes, either by lifting oneself with handrails on a chair and repositioning or tilting backwards in a wheelchair with reclining functions. Common techniques to maintain appropriate protein levels for skin integrity include oral protein drinks or powders that can be administered with or between meals to make sure appropriate serum prealbumin levels are maintained. Weekly monitoring of prealbumin levels can help guide dietary recommendations, and lower serum values generally indicate a greater need for oral protein supplementation. Regular inspection of the skin and proper bed positioning can also help to prevent further skin complications ${ }^{[53]}$. Appropriate bed positioning includes the use of pillows to alleviate pressure from bony prominences.

Sexual dysfunction is a complication of spinal cord tumors that can be particularly distressing. It may be the result of neurological damage from spinal cord compression, the primary diagnosis of cancer, or treatment effects of acute oncological interventions on the spinal cord itself. Both spinal cord injury and cancer may cause changes in body image, sensation, and function that may alter the person's perception of sexual attractiveness ${ }^{[54,55]}$. The rehabilitation program should include assessment of the patient's neurological injury and the impact of this injury on the patient's sexual response ${ }^{[56]}$. The extent of sexual dysfunction will be dependent upon whether the patient has complete or incomplete spinal cord injury. Furthermore radiation therapy, chemotherapy, and depression may affect sexual function. The bulbocavernosous reflex (BCR) is a common test that evaluates completeness of an injury specifically as it relates to involvement of the conus medullaris and sacral roots, and helps determine an individual's capability for erection ${ }^{[56,57]}$. A positive response involves stimulation of the glans penis or vulva with expected anal contraction. Both psychogenic and reflexogenic erections are parasympathetic in nature, whereas psychogenic control may be possible through sympathetic nervous system stimulation ${ }^{[58]}$. For patients with complete spinal cord injury and absence of the BCR, the ability for reflexogenic erections and lubrication is diminished. Physiological orgasm is unlikely in patients with complete injuries with absence of BCR and anal wink reflex ${ }^{[56,59]}$. Treatment options for males experiencing sexual dysfunction include education, counseling, oral medications that increase blood flow to facilitate erection such as sildenafil, and assistive devices (such as vacuum assisted device or pumps, and intraurethral agents or intracavernous injection therapy with prostaglandins) ${ }^{[56]}$. Interventions for females are less well established, although oral sildenafil has been used to help stimulate blood flow to the female genitourinary and reproductive systems, which may help improve physiological processes for intercourse. 


\section{The impact of rehabilitation}

Appropriate decisions for plans of care should account for acknowledgement of the phase of a patient's illness and the risks versus benefits of acute cancer intervention and treatment ${ }^{[60]}$. Although the knowledge bases relevant to cancer rehabilitation are growing, there is a relatively small amount of data that specifically addresses issues of functionality, QOL, and clinical guidelines for the spinal cord tumor patient. For this reason, the following data supporting rehabilitation intervention is classified according to evidence based guidelines (see Table 1) and ranges from IIA, IIB, III, and IV status. In addition, on-line resources have been provided that may be beneficial for clinicians, patients, and family members to help with care (see Table 2).

Table 1. Levels of evidence guidelines ${ }^{[78]}$

IA

IB

IIA

IIB

III

IV
Evidence from meta-analysis of randomized controlled trials

Evidence from at least one randomized controlled trial

Evidence from at least one controlled study without randomization

Evidence from at least one other type of quasi-experimental study

Evidence from non-experimental descriptive studies, such as comparative studies, correlation studies, and case-control studies Evidence from expert committee reports or opinions or clinical experience of respected authorities, or both

Table 2. Resources for individuals suffering from spinal cord neoplasm

\section{On-Line Resources for Clinicians, Patients, and Families}

\begin{tabular}{lll}
\hline $\begin{array}{l}\text { The American Cancer Society: Brain } \\
\text { and Spinal Cord Tumors in Adults }\end{array}$ & NINDS Brain and Spinal Tumors & The Spinal Cord Tumor Association \\
(http://www.cancer.org/cancer) & Information Page & (http://www.ninds.nih.gov//www.spinalcordtumor.org/) \\
\hline
\end{tabular}

With a diagnosis of spinal tumor, patients face a difficult adjustment due to denial of their disability, understanding new boundaries, concern about dependence on others, and learning to live within a new normality ${ }^{\text {[61] }}$. QOL is an important consideration for all cancer patients, and is a major focus of the rehabilitation plan of care. Although there is a scarcity of data relating rehabilitation, QOL, and spinal cord tumors, improvement in QOL remains a priority amongst rehabilitation care providers. Unfortunately, discrepancies exist between the perception of QOL for health care professionals and patients, and may be affected by both physical and non-physical issues, including independence, freedom from pain, and family support ${ }^{[62]}$. When designing a rehabilitation program, special attention is needed regarding individuals’ perception of QOL, which could be influenced by spiritual well-being, level of education, and desired functional outcome as they relate to activities of daily living and mobility ${ }^{[63]}$. Understanding QOL requires a multifactorial approach that incorporates physical, emotional, spiritual, social, and cognitive well-being. One specific intervention that may improve QOL in cancer patients is exercise intervention ${ }^{[41]}$. Positive effects have been noted as it relates to decreased nausea, weight gain, muscle atrophy, and fatigue. However, a majority of cancer patients do not participate in structured exercise programs; barriers that are often cited include: illness, joint stiffness, fatigue, pain, lack of motivation, weakness, lack of interest, and fear of falling ${ }^{[28]}$. When attempting to establish exercise programs for cancer patients, physical and occupational therapists with cancer rehabilitation experience can be a unique resource to help design interventions that are specific to the needs of patients with anticipated improvement in functional and QOL measures ${ }^{[64]}$. It must be noted, however, that prognosis should still be an important factor when designing the goals of a cancer rehabilitation program for all oncological populations ${ }^{[65]}$. For example, in a patient who is newly diagnosed with paraplegia from spinal cord tumor with a good long term prognosis, the focus of rehabilitation care is to allow the individual to be as independent as possible. Specific emphasis on upper extremity strengthening for mobility in a manual wheelchair, self-catheterization to empty the bladder, 
and home modifications allow for easier transition to the home environment. On the other hand, if an individual has quadriplegia with less than 6 months to live, the rehabilitation team may instead design a treatment plan that allows patients to independently direct their care, family members to learn how to transfer the patient using a lift, empty catheter bags for indwelling urinary catheters, or learn positioning techniques that minimize pain but provide appropriate pressure relief to prevent skin ulcerations.

Successful outcomes with the neuro-oncological patients depend upon timely recognition of functional problems and prompt referral for rehabilitation to help improve patient independence ${ }^{[41]}$. When evaluating functional outcomes for individuals suffering from spinal cord tumors, specific areas of focus include mobility, activities of daily living, bowel and bladder management, equipment evaluations, and family education in preparation for the transition to home ${ }^{[66]}$. Patients with benign tumors of the spinal cord tend to have the most improved neurological recoveries ${ }^{[67]}$. However individuals with malignant spinal cord tumors have also shown overall improvements in function, mood, QOL, and survival after aggressive interventions involving physical therapy, occupational therapy, and rehabilitation nursing at an acute inpatient rehabilitation hospital. Over $84 \%$ of patients with neoplastic spinal cord compression were able to discharge to home and they maintained improvements in upper and lower extremity dressing, grooming, toileting, tub transfers, wheelchair use, ambulation, and stair climbing 3 months after discharge ${ }^{[29]}$. Patients with American Spinal Asia Injury Impairment Scale A to $\mathrm{C}$ classification also experienced decreased pain, utilization of opioids, and measures of depression. They were more satisfied with life, and had better ability to transfer independently and manage bowel and bladder programs at home ${ }^{[68]}$. Appropriate bowel and bladder care is important to prevent major complications and discomfort from insensate skin due to neoplastic SCI ${ }^{[69]}$. Use of incentive spirometry, optimal nutritional supplementation, management of mood, and education in skin care issues contributed to an improved survival of 20 weeks ${ }^{[70]}$. Patients who survived greater than 1 year after discharge from inpatient rehabilitation experienced less medical complications, higher Frankel classification level (D), and decreased return admissions to the hospital ${ }^{[71]}$. Additional factors that could improve survival include less aggressive tumor pathology, slow progression of neurological symptoms, treatment with both surgery and radiation therapy, SCI as the presenting sign of malignancy, partial bowel control on admission, and partial independence regarding transfers at the time of admission to rehabilitation ${ }^{[72]}$. Longer term survival for spinal cord malignancy has been noted for: total functional independence measure (FIM) score of 65 or greater on admission; Frankel classification of B, C, or D; good wheelchair mobility; and good walking ability ${ }^{[73]}$. In contrast, patients with total FIM gain less than or equal to 13 had significantly poorer survival, though it has been noted that an increased length of stay did lead to higher overall FIM changes ${ }^{[5]}$. It should be noted, however, that patients with primary tumors who completed inpatient rehabilitation programs had a median survival of 9.5 months with 1 year survival of $47.4 \%$ and 5 year survival of $10.5 \%$, whereas patients with secondary tumors had a median survival of 2.8 months with 1 year survival of $21.4 \%$ and 5 year survival of $3.6 \%{ }^{[74]}$.

When evaluating rehabilitation potential, mood and psychological status are also important considerations that may help to predict outcomes for the spinal cord tumor population. Psycho-oncology attempts to combine biological and psychological approaches to address cancer related symptoms in hopes for improved overall outcomes ${ }^{[79]}$. Psycho-social interventions may improve psychological and physiological adaptation indicators in cancer patients ${ }^{[80]}$. In addition, supportive-expressive group therapy has been shown to decrease pain symptoms in metastatic disease ${ }^{[81]}$. Opportunities to express emotion have also shown increased physical health and vigor ${ }^{[82]}$. Although physical exercise has also shown been shown to improve psychological well-being, results may vary according to stage of the disease, lifestyle of the individuals, and medical treatment received ${ }^{[83]}$. The effects of psychology on functional status and quality of life are important considerations when developing rehabilitation plans of care, and should be a focus of nurses, physicians, psychologists, social workers, and therapists. However, to the best of our knowledge, evidence based data is lacking correlating functional outcomes with psycho-oncological intervention for the spinal cord tumor patient. Future research is necessary to determine how clinical psychological strategies can be used to help improve the overall rehabilitation plan of care.

It should be noted, however, that several medical complications from the cancer itself can impair functional recovery and QOL, regardless of the primary source of the tumor. When designing a rehabilitation program for patients suffering with 
spinal cord tumors, considerations should be made to accommodate concomitant cancer related disorders as they relate to overall functional outcomes. Such co-morbidities may include cachexia, fatigue, psychological factors, and adverse effects from primary treatment of the oncological process. Immobility, effects from pain medication, and malnutrition may affect GI motility and nutrition and must be addressed when establishing both medical and functional goals for rehabilitation. Valsalva maneuvers used to trigger bowel movements for individuals with partial sensation may also cause significant back pain due to spinal involvement of the tumor. In addition, indwelling urinary catheters may be reasonable options for bladder management in individuals who cannot void spontaneously or who have contraindications to receive intermittent catheterization, such as severe thrombocytopenia or leukopenia ${ }^{[75]}$. Patients with neoplastic spinal involvement may lack the ability to perform intermittent catheterization due to pain, and neurogenic complications from upper motor neuron lesions may make indwelling urinary catheter use appropriate in spite of increased risks of complications such as UTI or bladder calculi ${ }^{[76]}$. Of note however, for patients who complete inpatient rehabilitation with normal bladder function and survive greater than 1 month after discharge, $72 \%$ retained normal bladder function ${ }^{\text {[77] }}$. Hence, when designing the program of rehabilitation, the plan of care should be aggressive to prevent complications from injury to the spinal cord, but should also be mindful that the rehabilitation interventions themselves may not always be feasible depending on the medical co-morbidities associated with the spinal cord tumor diagnosis.

\section{Conclusions}

Approaches to the treatment of individuals with spinal cord tumors require a multidisciplinary approach, drawing upon the experiences and skills of nurses, physiatrists, and therapists for maximal physical gains. Although these patients often have significant medical co-morbidities, they can be expected to make improvements regarding their medical status, functionality, and QOL. Specific considerations should be made relative to oncological interventions for treatment and symptom management to achieve the most improved outcomes, but prognosis should always play a role when implementing a medical and rehabilitation plans of care.

\section{References}

[1] Cromes GF. Implementation of interdisciplinary cancer rehabilitation. Rehabil Counseling Bull. 1978;21:230-237.

[2] Yoshioka H. Rehabilitation for the terminal cancer patients. Am Phys Med Rehabil. 1994;73:199-206. http://dx.doi.org/10.1097/00002060-199406000-00009

[3] Blaney JM, Lowe-Strong A, Rankin-Watt J, Campbell A, Gracey JH. Cancer survivors’ exercise barriers, facilitators and preferences in the context of fatigue, quality of life and physical activity participation: a questionsnaire-survey. Psychooncology. 2013;22:186-194. PMid:23296635 http://dx.doi.org/10.1002/pon.2072

[4] Carr J, Finlay P, Pearson D, Thompson K, White H. Neurological tumours and associated conditions. In: Rankin J, Robb K, Murtagh N, Cooper, J, Lewis S, (ed.) Rehabilitation in Cancer Care. Oxford: Blackwell Publishing Ltd; 2008. p. 99-108.

[5] Tang V, Harvey D, Park Dorsay J, Jiang S, Rathbone MP. Prognostic indicators in metastatic spinal cord compression: using Functional Independence Measure and Tokuhashi scale to optimize rehabilitation planning. Spinal Cord. 2007;45(10):671-7. PMid:17228353 http://dx.doi.org/10.1038/sj.sc.3102024

[6] Abrahm JL, Banffy MB, Harris MB. Spinal cord compression in patients with advanced metastatic disease: "all I care about is walking and living my life.” JAMA. 2008;299(8):937-46. PMid:18314436 http://dx.doi.org/10.1001/jama.299.8.937

[7] Guo Y, Young B, Palmer JL, Mun Y, Bruera E. Prognostic factors for survival in metastatic spinal cord compression: a retrospective study in a rehabilitation setting. Am J Phys Med Rehabil. 2003;82(9):665-8. PMid:12960907 http://dx.doi.org/10.1097/01.PHM.0000083662.85497.1F

[8] Palacio A, Calmels P, Genty M, Le-Quang B, Beuret-Blanquart F. Oncology and physical medicine and rehabilitation. Ann Phys Rehabil Med. 2009;52(7-8):568-78. PMid:19720573 http://dx.doi.org/10.1016/j.rehab.2009.05.004

[9] Jacobs WB, Perrin RG. Evaluation and treatment of spinal metastases: an overview. Neurosurg Focus. 2001;11(6): E10. PMid:16463993 http://dx.doi.org/10.3171/foc.2001.11.6.11

[10] McKinley WO, Seel RT, Hardman JT. Nontraumatic spinal cord injury: incidence, epidemiology, and functional outcome. Arch Phys Med Rehabil. 1999;80(6):619-23. http://dx.doi.org/10.1016/S0003-9993(99)90162-4 
[11] Heary RF, Bono CM. Metastatic spinal tumors. Neurosurg Focus. 2001;11(6):E1. PMid:16463992 http://dx.doi.org/10.3171/foc.2001.11.6.2

[12] Chamberlain MC, Tredway TL. Adult primary intradural spinal cord tumors: a review. Curr Neurol Neurosci Rep. 2011;11(3):320-8. PMid:21327734 http://dx.doi.org/10.1007/s11910-011-0190-2

[13] Bowers DC, Weprin BE. Intramedullary spinal cord tumors. Curr Treat Options Neurol. 2003;5(3):207-12. http://dx.doi.org/10.1007/s11940-003-0011-2

[14] Drudge-Coates L, Rajbabu K. Diagnosis and management of malignant spinal cord compression: part 1. Int J Palliat Nurs. 2008;14(3):110-6. PMid:18414334

[15] Fattal C, Fabbro M, Gelis A, Bauchet L. Metastatic paraplegia and vital prognosis: perspectives and limitations for rehabilitation care. part 1. Arch Phys Med Rehabil. 2011;92(1):125-33. PMid:21187215 http://dx.doi.org/10.1016/j.apmr.2010.09.017

[16] Cowap J, Hardy JR, A’Hern R. Outcome of malignant spinal cord compression at a cancer center: implications for palliative care services. J Pain Symptom Manage. 2000;19(4):257-64. http://dx.doi.org/10.1016/S0885-3924(00)00110-X

[17] Wetzel FT, Phillips FM. Orthopedic management of metastatic disease of the spine. Orthop Clin North Am. 2000;31(4):611-21. http://dx.doi.org/10.1016/S0030-5898(05)70179-6

[18] Sundaresan N, Sachdev VP, Holland JF, Moore F, Sung M, Paciucci PA et al. Surgical treatment of spinal cord compression from epidural metastasis. J Clin Oncol. 1995;13(9):2330-5. PMid:7666091

[19] Rades D, Karstens JH. A comparison of two different radiation schedules for metastatic spinal cord compression considering a new prognostic factor. Strahlenther Onkol. 2002;178(10):556-61. PMid:12386787 http://dx.doi.org/10.1007/s00066-002-0980-1

[20] Rompe JD, Hopf CG, Eysel P. Outcome after palliative posterior surgery for metastatic disease of the spine-evaluation of 106 consecutive patients after decompression and stabilisation with the Cotrel-Dubousset instrumentation. Arch Orthop Trauma Surg. 1999;119(7-8):394-400. PMid:10613227 http://dx.doi.org/10.1007/s004020050008

[21] Drudge-Coates L, Rajbabu K. Diagnosis and management of malignant spinal cord compression: part 2. Int J Palliat Nurs. 2008;14(4):175-80. PMid:18681345

[22] Putz C, van Middendorp JJ, Pouw MH, Moradi B, Rupp R, Weidner N et al. Malignant cord compression: a critical appraisal of prognostic factors predicting functional outcome after surgical treatment. J Craniovertebr Junction Spine. 2010;1(2):67-73. PMid:21572627 http://dx.doi.org/10.4103/0974-8237.77670

[23] Le H, Balabhadra R, Park J, Kim D. Surgical treatment of tumors involving the cervicothoracic junction. Neurosurg Focus. 2003;15(5):E3. PMid:15323460 http://dx.doi.org/10.3171/foc.2003.15.5.3

[24] Milross CG, Davies MA, Fisher R, Mameghan J, Mameghan H. The efficacy of treatment for malignant epidural spinal cord compression. Australas Radiol. 1997;41(2):137-42. PMid:9153809

[25] Yang S, Yang X, Hong G. Surgical treatment of one hundred seventy-four intramedullary spinal cord tumors. Spine. 2009;34(24):2705-10. PMid:19910775 http://dx.doi.org/10.1097/BRS.0b013e3181b43484

[26] Zaidat OO, Ruff RL. Treatment of spinal epidural metastasis improves patient survival and functional state. Neurology. 2002;58(9):1360-6. http://dx.doi.org/10.1212/WNL.58.9.1360

[27] Aass N, Fossa SD. Pre- and post-treatment daily life function in patients with hormone resistant prostate carcinoma treated with radiotherapy for spinal cord compression. Radiother Oncol. 2005;74(3):259-265. PMid:15763306 http://dx.doi.org/10.1016/j.radonc.2004.12.001

[28] Raco A, Esposito V, Lenzi J, Piccirilli M, Delfini R, Cantore G. Long-term follow-up of intramedullary spinal cord tumors: a series of 202 cases. Neurosurgery. 2005;56(5):972-81. PMid:15854245

[29] McKinley WO, Conti-Wyneken AR, Vokac CW, Cifu DX. Rehabilitative functional outcome of patients with neoplastic spinal cord compression. Arch Phys Med Rehabil. 1996;77(9):892-5. http://dx.doi.org/10.1016/S0003-9993(96)90276-2

[30] Foley KM. The treatment of pain in the patient with cancer. CA Cancer J Clin. 1986;36(4):194-215. PMid:2425909 http://dx.doi.org/10.3322/canjclin.36.4.194

[31] Collins JJ, Grier HE, Kinney HC, Berde CB. Control of severe pain in children with terminal malignancy. J Pediatr. 1995;126(4):653-7. http://dx.doi.org/10.1016/S0022-3476(95)70370-5

[32] Bach F, Larsen BH, Rohde K, Borgesen SE, Gjerris F, Boge-Rasmussen T et al. Metastatic spinal cord compression. occurrence, symptoms, clinical presentations and prognosis in 398 patients with spinal cord compression. Acta Neurochir (Wien). 1990;107(1-2):37-43. http://dx.doi.org/10.1007/BF01402610

[33] Helweg-Larsen S, Sorensen PS. Symptoms and signs in metastatic spinal cord compression: a study of progression from first symptom until diagnosis in 153 patients. Eur J Cancer. 1994;30A(3):396-8. http://dx.doi.org/10.1016/0959-8049(94)90263-1

[34] Cheville AL. Palliative care. In: DeLisa JA (ed.) Physical Medicine \& Rehabilitation: Principles and Practice. Philadelphia: Lippincott Williams \& Wilkins; 2005. p. 531-55. 
[35] Kirshblum S, O’Dell MW, Ho C, Barr K. Rehabilitation of persons with central nervous system tumors. Cancer. 2001;92(4 Suppl):1029-38. http://dx.doi.org/10.1002/1097-0142(20010815)92:4+<1029::AID-CNCR1416>3.0.CO;2-P

[36] Jadad AR, Browman GP. The WHO analgesic ladder for cancer pain management. stepping up the quality of its evaluation. JAMA. 1995;274(23):1870-3. PMid:7500538 http://dx.doi.org/10.1001/jama.1995.03530230056031

[37] Dworkin RH, O’Connor AB, Backonja M, Farrar JT, Finnerup NB, Jensen TS et al. Pharmacologic management of neuropathic pain: evidence-based recommendations. Pain. 2007;132(3):237-51. PMid:17920770 http://dx.doi.org/10.1016/j.pain.2007.08.033

[38] Levendoglu F, Ogun CO, Ozerbil O, Ogun TC, Ugurlu H. Gabapentin is a first line drug for the treatment of neuropathic pain in spinal cord injury. Spine. 2004;29(7):743-51. PMid:15087796 http://dx.doi.org/10.1097/01.BRS.0000112068.16108.3A

[39] Cardenas DD, Warms CA, Turner JA, Marshall H, Brooke MM, Loeser JD. Efficacy of amitriptyline for relief of pain in spinal cord injury: results of a randomized controlled trial. Pain. 2002;96(3):365-73. http://dx.doi.org/10.1016/S0304-3959(01)00483-3

[40] Siddall PJ, Cousins MJ, Otte A, Griesing T, Chambers R, Murphy TK. Pregabalin in central neuropathic pain associated with spinal cord injury: a placebo controlled trial. Neurology. 2006;67(10):1792-800. PMid:17130411 http://dx.doi.org/10.1212/01.wnl.0000244422.45278.ff

[41] Fialka-Moser V, Crevenna R, Korpan M, Quittan. Cancer rehabilitation particularly with aspects onphysical impairments. J Rehabil Med. 2003;35:153-162. PMid:12892240 http://dx.doi.org/10.1080/16501970306129

[42] Stiens SA, Bergman SB, Goetz LL. Neurogenic bowel dysfunction after spinal cord injury: clinical evaluation and rehabilitative management. Arch Phys Med Rehabil. 1997;78(3 Suppl):S86-S102. http://dx.doi.org/10.1016/S0003-9993(97)90416-0

[43] Schiff D. Spinal cord compression. Neurol Clin. 2003;21(1):67-86. http://dx.doi.org/10.1016/S0733-8619(02)00033-6

[44] Miaskowski C, Cleary J, Burney R. Guideline for the management of cancer pain in adults and children, APS clinical practice guideline series, No 3. Glenview IL: American Pain Society: 2005.

[45] Henry RF, Rilart R. Tumors of the spine and spinal cord. In: Kirshblum SK, Campagnolo DI, DeLisa JA, (ed.) Spinal Cord Medicine. Philadelphia: Lippincott Williams \& Wilkins; 2002. p. 480-97.

[46] Davis A, Nagelhout MJ, Hoban M, Barnard B. Bowel management: a quality assurance approach to upgrading programs. J Gerontol Nurs. 1986;12(5):13-7. PMid:3635553

[47] Kirk PM, King RB, Temple R, Bourjaily J, Thomas P. Long-term follow-up of bowel management after spinal cord injury. SCI Nurs. 1997;14(2):56-63. PMid:9295753

[48] Zejdlik CP. Reestablishing bowel control. In: Management of spinal cord injury, Second edition, edited by CP Zejdlik, 397-416. 1992.

[49] Clinical practice guidelines: neurogenic bowel management in adults with spinal cord injury. Spinal Cord Medicine Consortium. J Spinal Cord Med. 1998;21(3):248-93. PMid:9863937

[50] Consortium for Spinal Cord Medicine. Bladder management for adults with spinal cord injury: a clinical practice guideline for health-care providers. J Spinal Cord Med. 2006;29(5):527-73. PMid:17274492

[51] Ching W. Luhmann M. Neuro-oncologic physical therapy for the older person. Top Geriatr Rehabil. 2011;27(3):184-192. PMid:22049262

[52] Consortium for Spinal Cord Medicine Clinical Practice Guidelines. Pressure ulcer prevention and treatment following spinal cord injury: a clinical practice guideline for health-care professionals. J Spinal Cord Med. 2001;24(Suppl 1):S40-101. PMid:11958176

[53] Beiner J, Grauer J, Kwon B, Vaccaro A. Postopertive wound infections of the spine. Neurosurg Focus. 2003;15 (3):1-5. http://dx.doi.org/10.3171/foc.2003.15.3.14

[54] Pelusi J. Sexuality and body image. research on breast cancer survivors documents altered body image and sexuality. Am J Nurs. 2006;106(3 Suppl):32-8. PMid:16481849 http://dx.doi.org/10.1097/00000446-200603003-00013

[55] Anderson KD, Borisoff JF, Johnson RD, Stiens SA, Elliott SL. Long-term effects of spinal cord injury on sexual function in men: implications for neuroplasticity. Spinal Cord. 2007;45(5):338-48. PMid:17016492

[56] Consortium for Spinal Cord Medicine. Sexuality and reproductive health in adults with spinal cord injury: a clinical practice guideline for health-care professionals. J Spinal Cord Med. 2010;33(3):281-336. PMid:20737805

[57] Sipski M, Alexander CJ, Gomez-Marin O. Effects of level and degree of spinal cord injury on male orgasm. Spinal Cord. 2006;44(12);798-804. PMid:16801932 http://dx.doi.org/10.1038/sj.sc.3101954

[58] Sipski M, Alexander C, Gomez-Marin O, Spalding J. The effects of spinal cord injury on psychogenic sexual arousal in males. J Urol. 2007;177(1):247-51. PMid:17162056 http://dx.doi.org/10.1016/j.juro.2006.08.059

[59] Sipski ML, Alexander CJ, Rosen R. Sexual arousal and orgasm in women: effects of spinal cord injury. Ann Neurol. 2001;49(1):35-44. http://dx.doi.org/10.1002/1531-8249(200101)49:1<35::AID-ANA8>3.0.CO;2-J

[60] Hicks F, Thom V, Alison D, Corcoran G. Spinal cord compression: the hospice perspective. J Palliat Care. 1993;9(3):9-13. PMid:8068066 
[61] Eva G, Paley J, Miller M, Wee B. Patients’ constructions of disability in metastatic spinal cord compression. Palliat Med. 2009;23(2):132-40. PMid:19073781 http://dx.doi.org/10.1177/0269216308099959

[62] Levack P, Graham J, Kidd J. Listen to the patient: quality of life of patients with recently diagnosed malignant cord compression in relation to their disability. Palliat Med. 2004;18(7):594-601. PMid:15540667 http://dx.doi.org/10.1191/0269216304pm925oa

[63] Tate DG, Forchheimer M. Quality of life, life satisfaction, and spirituality: comparing outcomes between rehabilitation and cancer patients. Am J Phys Med Rehabil. 2002;81(6):400-10. http://dx.doi.org/10.1097/00002060-200206000-00002

[64] Blaney JM, Lowe-Strong A, Rankin J, Campbell A, Allen J, Gracey JH.The cancer rehabilitation journey: barriers to and facilitators of exercise among patients with cancer-related fatigue. Phys Ther. 2010;90:1135-1147. PMid:20558566 http://dx.doi.org/10.2522/ptj.20090278

[65] Fattal C, Fabbro M, Rouays-Mabit H, Verollet C, Bauchet L. Metastatic paraplegia and functional outcomes: perspectives and limitations for rehabilitation care. part 2. Arch Phys Med Rehabil. 2011;92(1):134-45. PMid:21187216 http://dx.doi.org/10.1016/j.apmr.2010.09.016

[66] Roonprapunt C, Houten JK. Spinal cord astrocytomas; presentation, management, and outcome. Neurosurg Clin N Am. 2006;17:29-36. PMid:16448905 http://dx.doi.org/10.1016/j.nec.2005.10.006

[67] Catz A, Goldin D, Fishel B, Ronen J, Bluvshtein V, Gelernter I. Recovery of neurologic function following nontraumatic spinal cord lesions in Israel. Spine. 2004;29(20):2278-82. PMid:15480141 http://dx.doi.org/10.1097/01.brs.0000142008.49907.c7

[68] Ruff RL, Ruff SS, Wang X. Persistent benefits of rehabilitation on pain and life quality for nonambulatory patients with spinal epidural metastasis. J Rehabil Res Dev. 2007;44(2):271-8. PMid:17551878 http://dx.doi.org/10.1682/JRRD.2007.01.0006

[69] Murray PK. Functional outcome and survival in spinal cord injury secondary to neoplasia. Cancer. 1985;55(1):197-201. http://dx.doi.org/10.1002/1097-0142(19850101)55:1<197::AID-CNCR2820550131>3.0.CO;2-F

[70] Ruff RL, Adamson VW, Ruff SS, Wang X. Directed rehabilitation reduces pain and depression while increasing independence and satisfaction with life for patients with paraplegia due to epidural metastatic spinal cord compression. J Rehabil Res Dev. 2007;44(1):1-10. PMid:17551853 http://dx.doi.org/10.1682/JRRD.2005.10.0168

[71] Eriks IE, Angenot EL, Lankhorst GJ. Epidural metastatic spinal cord compression: functional outcome and survival after inpatient rehabilitation. Spinal Cord. 2004;42(4):235-9. PMid:15060521 http://dx.doi.org/10.1038/sj.sc.3101555

[72] Hacking HG, Vans As HH, Lankhorst GJ. Factors related to the outcome of inpatient rehabilitation in patients with neoplastic epidural spinal cord compression. Paraplegia. 1993;31(6):367-74. PMid:8336999 http://dx.doi.org/10.1038/sc.1993.61

[73] Parsch D, Mikut R, Abel R. Postacute management of patients with spinal cord injury due to metastatic tumour disease: survival and efficacy of rehabilitation. Spinal Cord. 2003;41(4):205-10. PMid:12669084 http://dx.doi.org/10.1038/sj.sc.3101426

[74] Tan M, New P. Survival after rehabilitation for spinal cord injury due to tumor: a 12-year retrospective study. J Neurooncol. 2011;104(1):233-8. PMid:21104296 http://dx.doi.org/10.1007/s11060-010-0464-6

[75] Raven RW. Rehabilitation of patients with paralyses caused by cancer. Clin Oncol. 1975;1(3):263-8. PMid:174858

[76] Reitz A, Haferkamp A, Wagener N, Gerner HJ, Hohenfellner M. Neurogenic bladder dysfunction in patients with neoplastic spinal cord compression: adaptation of the bladder management strategy to the underlying disease. NeuroRehabilitation. 2006;21(1):65-9. PMid:16720939

[77] Conway R, Graham J, Kidd J, Levack P, Scottish Cord Compression Group. What happens to people after malignant cord compression? survival, function, quality of life, emotional well-being, and place of care 1 month after diagnosis. Clin Oncol. 2007;19(1):56-62. http://dx.doi.org/10.1016/j.clon.2006.11.010

[78] Shekelle PG, Woolf SH, Eccles M, Grimshaw J. Developing clinical guidelines. West J Med. 1999;170(6):348-51. PMid:18751155

[79] Kidman AD, Edelman S. Developments in Psycho-Oncology and Cognitive Behavior Therapy in Cancer. J Cogn Psychother. 1997;11(1):45-62.

[80] Antoni MH. Psychosocial intervention effects on adaptation, disease course and biobehavioral processes in cancer. Brain Behav Immun. 2012;30:S88-98. PMid:22627072 http://dx.doi.org/10.1016/j.bbi.2012.05.009

[81] Goodwin PJ, Leszcz M, Ennis M, Koopmans J, Vincent L, Guther H, Drysdale E, Hundleby M, Chochinov HM, Navarro M, Speca M, Hunter J. The effect of group psychosocial support on survival in metastatic breast cancer. N Engl J Med. 2001;345(24):1719-26. PMid:11742045 http://dx.doi.org/10.1056/NEJMoa011871

[82] Stanton AL, Danoff-Burg S, Cameron CL, Bishop M, Collins CA, Kirk SB, Sworowski LA, Twillman R. Emotionally expressive coping predicts psychological and physical adjustment to breast cancer. J Consult Clin Psychol. 2000;68(5):875-82. PMid:11068973 http://dx.doi.org/10.1037/0022-006X.68.5.875

[83] Knols R, Aaronson NK, Uebelhart D, Fransen J, Aufdemkampe G. Physical exercise in cancer patients during and after medical treatment: a systematic review of randomized and controlled clinical trials. J Clin Oncol. 2005;23(16):3830-42. PMid:15923576 http://dx.doi.org/10.1200/JCO.2005.02.148 